\title{
Neuroendocrine tumor of pancreas
}

INSERM

\section{Source}

INSERM. (1999). Orphanet: an online rare disease and orphan drug data base.

Neuroendocrine tumor of pancreas. ORPHA:97253

Pancreatic endocrine tumor, also known as pancreatic neuroendocrine tumor (PNET), describes a group of endocrine tumors originating in the pancreas that are usually indolent and benign, but may have the potential to be malignant. They can be functional, exhibiting a hormonal hypersecretion syndrome, but can be non-functional presenting with non-specific symptoms and include insulinoma, glucagonoma, VIPoma, somatostatinoma (SSoma), PPoma and Zollinger-Ellison syndrome (ZES, or gastrinoma) and other ectopic hormone producing tumors (such as GRFoma) (see these terms). 